Original Research Paper

\title{
Physical and Geometrical Effects on the Vibratory Pattern of a Pipe Carrying Fluid Flow
}

\author{
${ }^{1}$ Dahmane Mouloud, ${ }^{2}$ Samir Zahaf, ${ }^{3}$ Mawhoub Soubih, ${ }^{4}$ Benkhettab Mohamed and ${ }^{1}$ Djilali Boutchicha \\ ${ }^{I}$ Department of LMA, Mechanical Engineering, USTO-MB, BP 1055 El Menaour, Oran 31000, Algeria \\ ${ }^{2}$ Department of Technology, University of Djilali Bounaama-Khamis Meliana, Ain Defla-Algeria \\ ${ }^{3}$ Labortory of Mechanics and Energy, Chlef University Hassiba Benbouali, Chlef, Algeria \\ ${ }^{4}$ Department of Mechanical Engineering, Mostaganem University-Abdelhamid Ibn Badis, Algeria
}

\author{
Article history \\ Received: 06-07-2020 \\ Revised: 20-10-2020 \\ Accepted: 22-10-2020 \\ Corresponding Author: \\ Samir Zahaf \\ Department of Technology, \\ University of Djilali \\ Bounaama-Khamis Meliana, \\ Ain Defla-Algeria \\ Email: samir.zahaf@univ-dbkm.dz \\ zahafsamir1983@gmail.com
}

\begin{abstract}
In this research, the first natural frequencies and critical velocities of a fluid flow-conveying pipe are obtained with finite element method. By discretizing the structure wall and fluid flow, starting from beam type with two degrees of freedom per node. We determine the equation of motion from the fluid-structure coupling using Lagrange energy principle. Parameters frequencies and critical velocity of fluid flow are calculated by using a program developed on MATLAB. The results are compared with those predicted by the differential transformation method. Stability and instability properties of the system are analyzed after calculating the natural frequencies and the fluid critical velocity in terms of various parameters.
\end{abstract}

Keywords: Fluid-Conveying Pipe, Natural Frequencies, Critical Velocity, Elastic Foundation, Instability, MATLAB

\section{Introduction}

When a structure is contacted with a fluid, the elastic compartment undergoes a significant change; the increase of the natural frequencies observed during interaction of fluid with structure can even affect the system stability. Study of this subject is much ramified, Païdoussis (1970; 1981; 2014; Païdoussis and Besancon, 1981; Païdoussis and Curling, 1985; Païdoussis and Moon, 1988; Païdoussis et al., 2007) is the most famous researcher on the topic of mating and thanks to his research we obtained the linear and non-linear equation of the pipes motion under the influence of many factors. All these researches were gathered with others in a book (Païdoussis, 2014), in which he explores the concept of pipelines stability and instability. Doaré and de Langre (2002a-b; 2000; 2006), he touched better on the issue of instability, we find in his study that he studied instability in its two types (dynamic, static) and that is by calculating the frequencies in terms of the fluid critical velocity. A significant amount of research has been carried out the dynamics of cantilevered pipeconveying fluid, by means of linear mathematical models (Païdoussis, 2014) and there are other work in the same context, analytical, such as Galerkin method (Chellapilla and Simha, 2007; 2008), semi-analytical, by DQM in (Qian et al., 2009) and by DTM in (Ni et al., 2011), numerical by finite Element Method (FEM), in (Sadeghi and Karimi-Dona, 2011; Mostafa, 2014; Dahmane et al., 2016). There are many contemporary studies dealing with the subject of pipe vibration in term of fluid flow under physical and geometrical effects (Ghayesh et al., 2018a-b; Jiya et al., 2018; Zhang et al., 2018; Liang et al., 2018; Wang et al., 2018; Liu et al., 2018; Sazesh and Shams, 2019). All these studies did not take into consideration the concept of the range (field) instability as well as the analysis and the instability parameters, which constitutes an obstacle and challenge for engineers, especially in the heat exchangers as nuclear production, industry pipelines, fuel pipes in high duty engines, hydropower systems and solution mining applications.

In the present study, calculation methods have been developed for the free vibrations analysis of cantilevered pipe conveying fluid. The numerical methods were developed, modeling of structure (pipe)-incompressible fluid and was conducted by the standard finite element method, using beam type with two degrees of freedom per node. The proper frequencies and critical velocity of the system are calculated using a program developed on MATLAB. This allows us to study instability and discover its most important characteristics. 


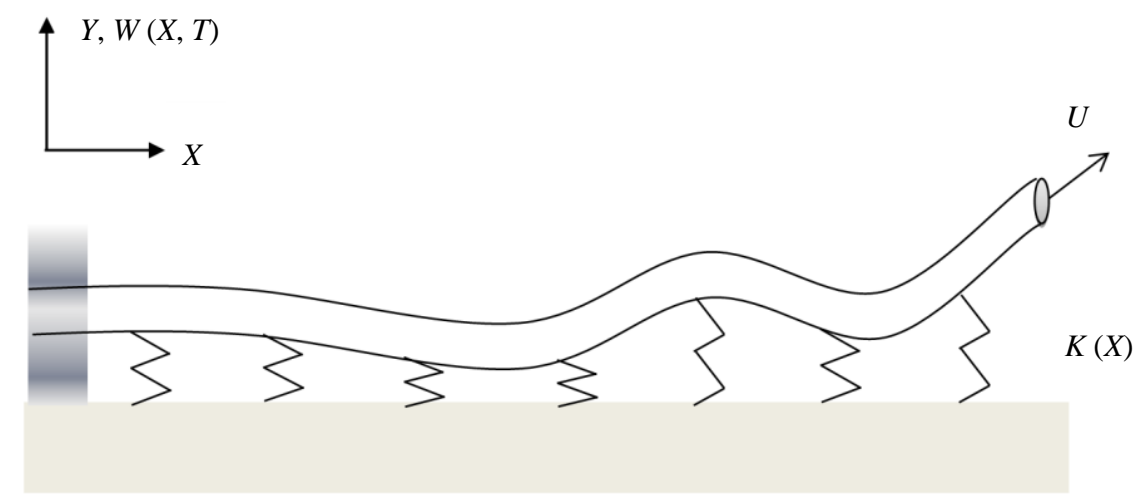

(a)

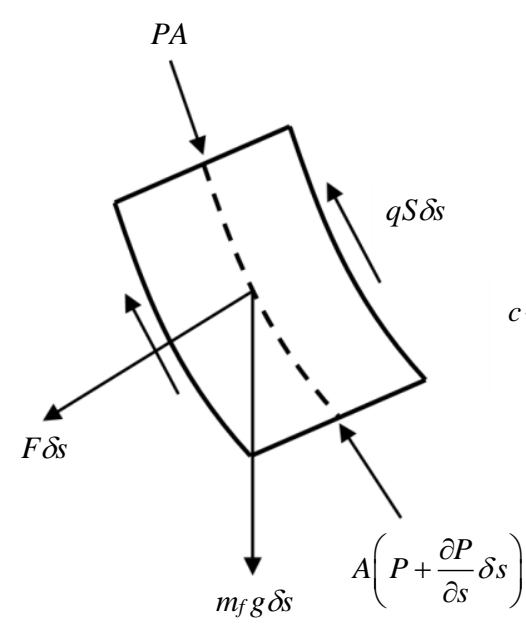

(b)

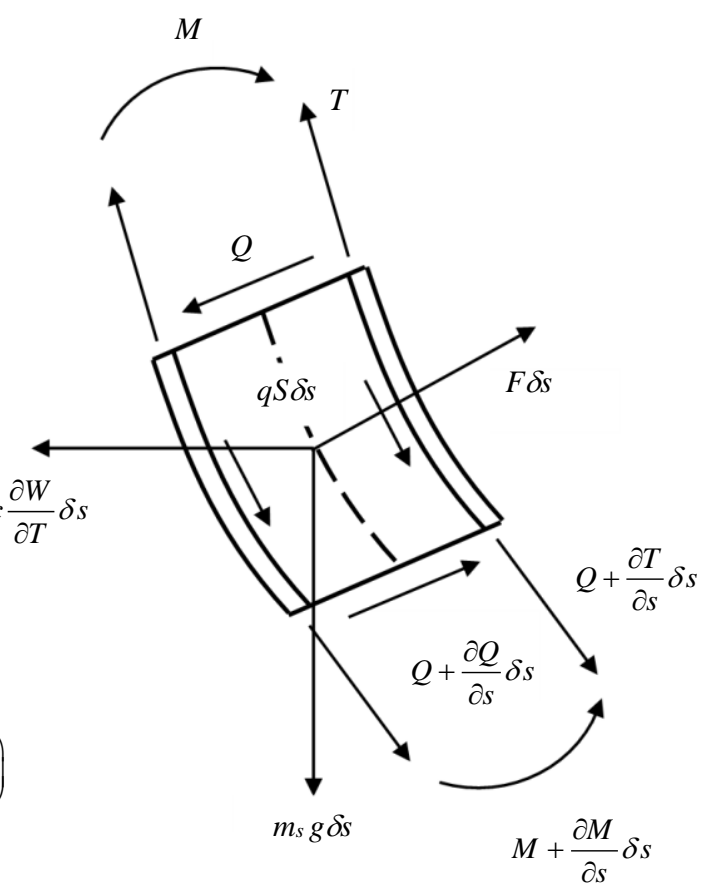

(c)

Fig. 1: (a) Cantilevered pipe-conveying fluid resting on an foundation elastic Winkler-type, (b) forces on fluid element; (c) forces and moments on pipe element $\delta$ s (Païdoussis, 2014)

\section{Differential Equation of Motion}

The problem to be considered is the vibration analysis of a fluid conveying pipe system on an elastic foundation Winkler-model. The derivation of the equation is based on bernoulli-euler elementary beam theory. The physical model of system is shown in Fig. 1a and $1 \mathrm{~b}$ shows forces on fluid element, Fig. 1c shows forces and pipe element moment.

The equation for conveying pipe carrying fluid on a Winkler elastic foundation is given as (Dahmane et al., 2016):

$$
\begin{aligned}
& E I \frac{\partial^{4} Y}{\partial X^{4}}+m_{f} U^{2} \frac{\partial^{2} Y}{\partial X^{2}}+2 m_{f} U \frac{\partial^{2} Y}{\partial X \partial T} \\
& +\left(m_{s}+m_{f}\right) \frac{\partial^{2} Y}{\partial T^{2}}+K Y=0
\end{aligned}
$$

where, the pipe is long and straight $L$ conveying an incompressible fluid with steady speed $U$; the motions are small $\delta s$. The elastic foundation Winkler-model is $K Y, m_{s}$ and $m_{f}$ the masses per unit length of the pipe and the fluid, respectively (Fig. 2). The Boundary conditions are: 


$$
\begin{aligned}
& \left.Y\right|_{X=0}=\left.\frac{\partial Y}{\partial X}\right|_{X=0}=\left.\frac{\partial^{2} Y}{\partial X^{2}}\right|_{X=L}=\left.\frac{\partial^{3} Y}{\partial X^{3}}\right|_{X=L}=0 \\
& \left.y\right|_{x=0}=\left.\frac{\partial y}{\partial x}\right|_{x=0}=\left.\frac{\partial^{2} y}{\partial x^{2}}\right|_{x=1}=\left.\frac{\partial^{3} y}{\partial x^{3}}\right|_{x=1}=0
\end{aligned}
$$

where, the non-dimensional parameters (Païdoussis, 2014), we obtain:

$$
\begin{aligned}
& x=X / Y, y=Y / L, t=\left(E I /\left(m_{f}+m_{s}\right)^{1 / 2}\right) T / L^{2}, \\
& \beta=m_{f} /\left(m_{f}+m_{s}\right), \\
& u=U L\left(m_{f} / E I\right)^{1 / 2}, k=K L / E I
\end{aligned}
$$

where, the potential (deformation) energy and the kinetic energy of the solid element expressed by:

$V_{1}=\frac{1}{2} \int_{0}^{L} E I\left(\frac{d^{2} W}{d X^{2}}\right)^{2} d X$

$E_{C s}=\frac{1}{2} \int_{0}^{L} m_{s} \frac{d^{2} W}{d T^{2}} d X$

The kinetic energy of the fluid element can be expressed by (Sadeghi and Karimi-Dona, 2011):

$$
E_{C f}=\frac{1}{2} \int m_{f}\left(U \frac{d W}{d X}+\frac{d W}{d T}\right)^{2} d X
$$

The potential energy over the length of elastic foundation can be expressed by ( $\mathrm{Ni}$ et al., 2011; Sadeghi and Karimi-Dona, 2011):

$V_{2}=\frac{1}{2} \int_{0}^{L} K W^{2} d X$

The equation of element deflection for straight two dimensional beam element could have the form (Rao, 2011):

$W(X, T)=\sum_{i=1}^{N} N_{i}(X) W_{i}(T)$

where, $\left[N_{i}\right]$ represent the shape function and $W_{i}(T)$ is the function which represents the shape of the displacements and rotations at nodes (Fig. 3 ).

Therefore, Equation (8) becomes:

$$
\begin{aligned}
& W(X, T)=N_{1}(X) W_{1}(T)+N_{2}(X) \theta_{1}(T) \\
& +N_{3}(X) W_{2}(T)+N_{4}(X) \theta_{1}(T)
\end{aligned}
$$

Forming shape functions:

$$
\left\{\begin{array}{l}
N_{1}=1-3 x^{2}+2 x^{3} \\
N_{2}=L\left(x-2 x^{2}+3 x^{3}\right) \\
N_{3}=3 x^{2}-2 x^{3} \\
N_{4}=L x^{2}(x-1)
\end{array}\right.
$$

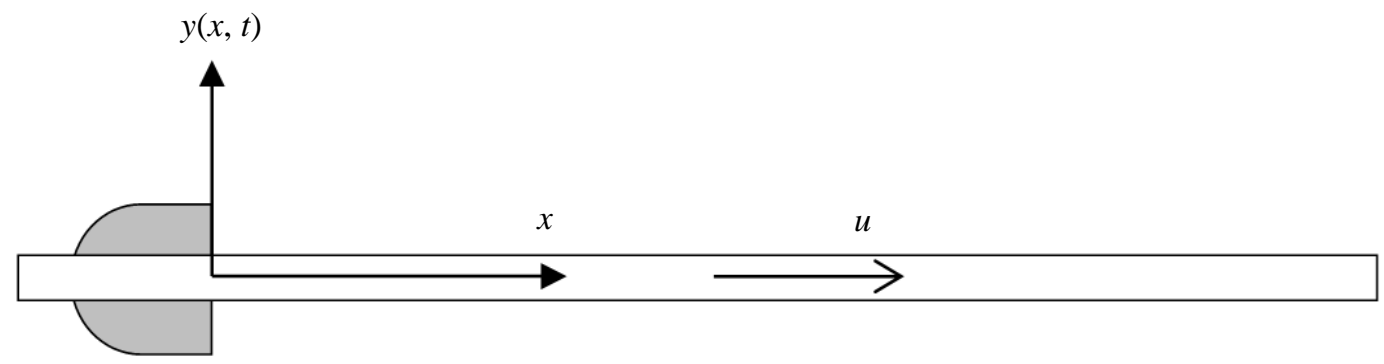

Fig. 2: Clamped-free Pipe with fluid

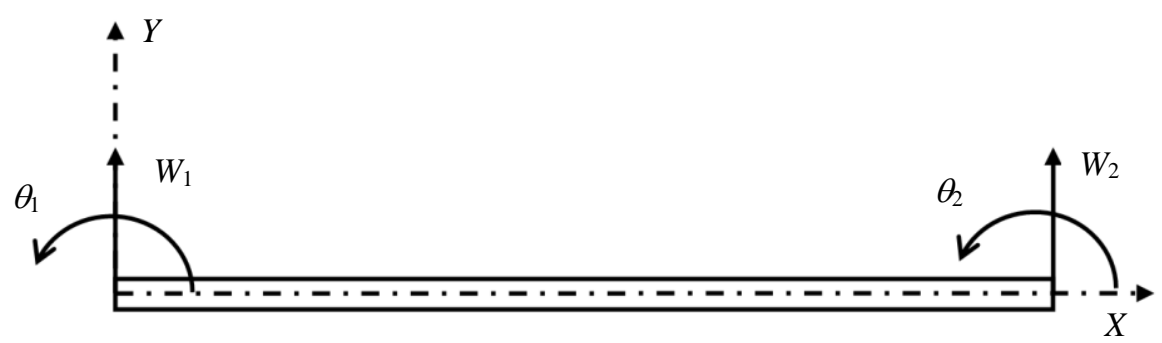

Fig. 3: Beam element nodal displacements; where, $W_{1}, \theta_{1}, W_{2}$ et $\theta_{2}$ : Are the displacements and rotations at the nodes. 


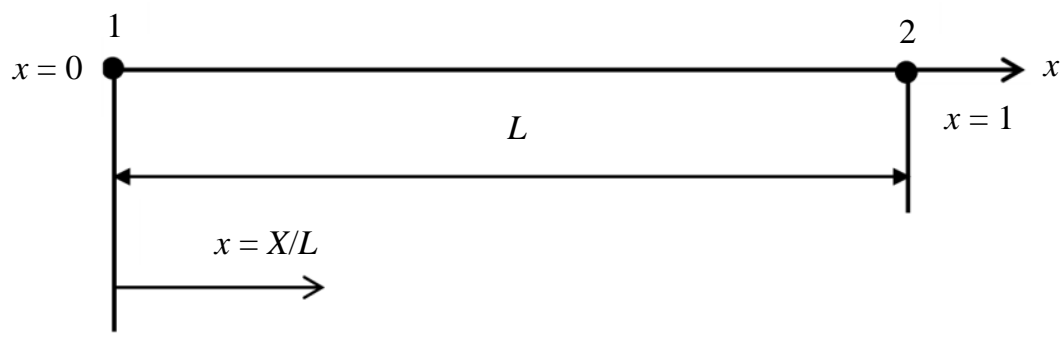

Fig. 4: Reference element

\section{Lagrange's Principle}

$\frac{d}{d T}\left(\frac{\partial E_{C}}{\partial \dot{q}_{i}}\right)-\frac{\partial E_{C}}{\partial \dot{q}_{i}}+\frac{\partial V}{\partial q_{i}}=0$

The standard equation of motion in the finite element form is:

$$
[M]\{\ddot{q}\}+(C)\{\dot{q}\}+([K])\{q\}=0
$$

Where:

$[M]=\left[M_{s}\right]+\left[M_{f}\right]$ : Elementary mass matrix of the system $[C]$ : $\quad$ Elementary damping matrix of the system

$[K]=\left[K_{s}\right]-\left[K_{f}\right]$ : Elementary stiffness matrix of the system

Considering the displacement vector as:

$$
\{Q\}=\{E\} \cdot \exp (\lambda t)
$$

$\lambda$ is eigenvalues of the system and the $\{E\}$ corresponding eigenvectors of this value.

The solution of Equation (12) is very complicated with presence of damping, so we use the variable change method (state-space):

$E \dot{z}+G z=0$

where the state variable is:

$$
z=\left\{\begin{array}{l}
\dot{q} \\
q
\end{array}\right\}
$$

The matrices $[E]$ and $[G]$ are calculated through variable-change as the following:

$$
\begin{aligned}
& E=\left[\begin{array}{cc}
M & 0 \\
0 & K
\end{array}\right] \\
& G=\left[\begin{array}{cc}
C & K \\
-K & 0
\end{array}\right]
\end{aligned}
$$

And the solution of equation is sought in the general form:

$z=\left\{\begin{array}{c}\lambda\{E\} \\ \{E\}\end{array}\right\} \exp (\lambda t)=\{\tilde{E}\} \exp (\lambda t)$

The system equation of government can be transformed from state space by:

$\left\{\left[\begin{array}{cc}0 & I \\ -M^{-1} K & -M^{-1} C\end{array}\right]-\lambda\left[\begin{array}{cc}I & 0 \\ 0 & I\end{array}\right]\right\}\left[\begin{array}{c}\lambda\{E\} \\ \{E\}\end{array}\right]=\left[\begin{array}{l}0 \\ 0\end{array}\right]$

$I$ is a unity matrix.

We ask ourselves:

$H=\left[\begin{array}{cc}0 & I \\ -M^{-1} K & -M^{-1} C\end{array}\right]$

Eigenvalues are complex; they give in the form:

$\lambda^{m}=\operatorname{Re}^{m}+j \omega^{m}$

Where:

Re: The real part of the eigenvalue and is the damping of our system

$\omega$ : The imaginary part of the eigenvalue, is therefore the proper pulsation of system

The stability and instability of the system under consideration is determined by the sign of real part and the natural frequencies values (the imaginary part) of the complex Eigen-value.

\section{Results and Discussion}

In studying and analyzing the concept of instability, the fundamental natural frequency of a pipe decreases with increasing fluid velocity. There are certain cases where a decrease in this natural frequency can be very important and with large fluid velocities, the pipe may become unstable. Results will be discussed for various values of $\beta$, length $L$, elastic foundation $k$ (Winkler type) and the instability parameters for clamped-free pipe. The 
elastic modulus of pipe is ( $E=207 \mathrm{GPa})$, pipe length is $(L=1 \div 2 \mathrm{~m})$, fluid density is $\left(m_{f}=1000 \mathrm{~kg} / \mathrm{m}^{3}\right)$, pipe density is $\left(m_{s}=7850 \mathrm{~kg} / \mathrm{m}^{3}\right)$, pipe thickness for $(\beta=0.1 \div$ $0.7)$ and the outer diameter of the pipe is $(0.03 \mathrm{~m})$. Frequencies results are displayed in terms of flow velocity and several parameters by figures, which come in three cases as follows: Mass ratio effect, length effect and elastic foundation effect.

\section{Mass Ratio Effect}

We calculated the natural frequency for first Eigen modes of clamped-free pipe for mass ratios, according to the fluid speed, Fig. 5 and 6.
Firstly, the program has been validated with reference (Ni et al., 2011), by calculating the first three dimensionless frequency as a function of the fluid velocity for cantilevered pipe with internal flow, where $\beta=0.5$. The Fig. 5 shows that the results obtained numerically are similar to those obtained by the analytical approach. The rigidity of a fixed-free beam system is very low than the other boundary conditions, it is preferable to use a dimensioning by calculating the natural frequencies. The Fig. 6 shows that the free vibration of the clamped-free pipe under an internal flow is very sensitive to the variation of mass ratios.

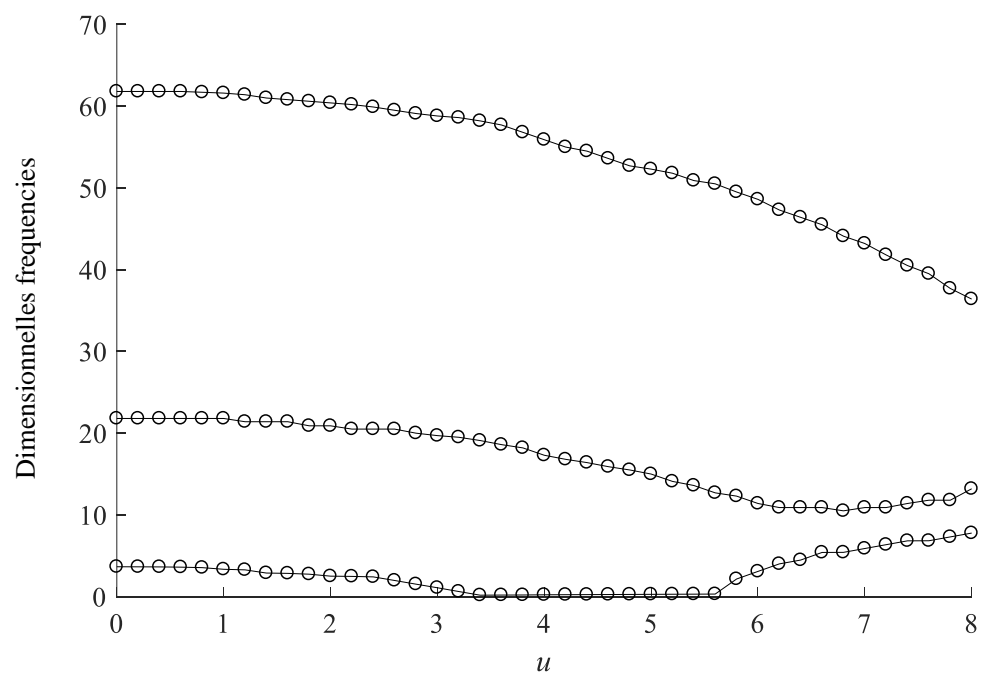

Fig. 5: The imaginary component of the dimensionless frequency as a various values of fluid velocity $(u)$, for the lowest three modes of a clamped-free pipe conveying fluid, comparison DTM (Ni et al., 2011) (ooo) and FEM (-), $\beta=0.5$

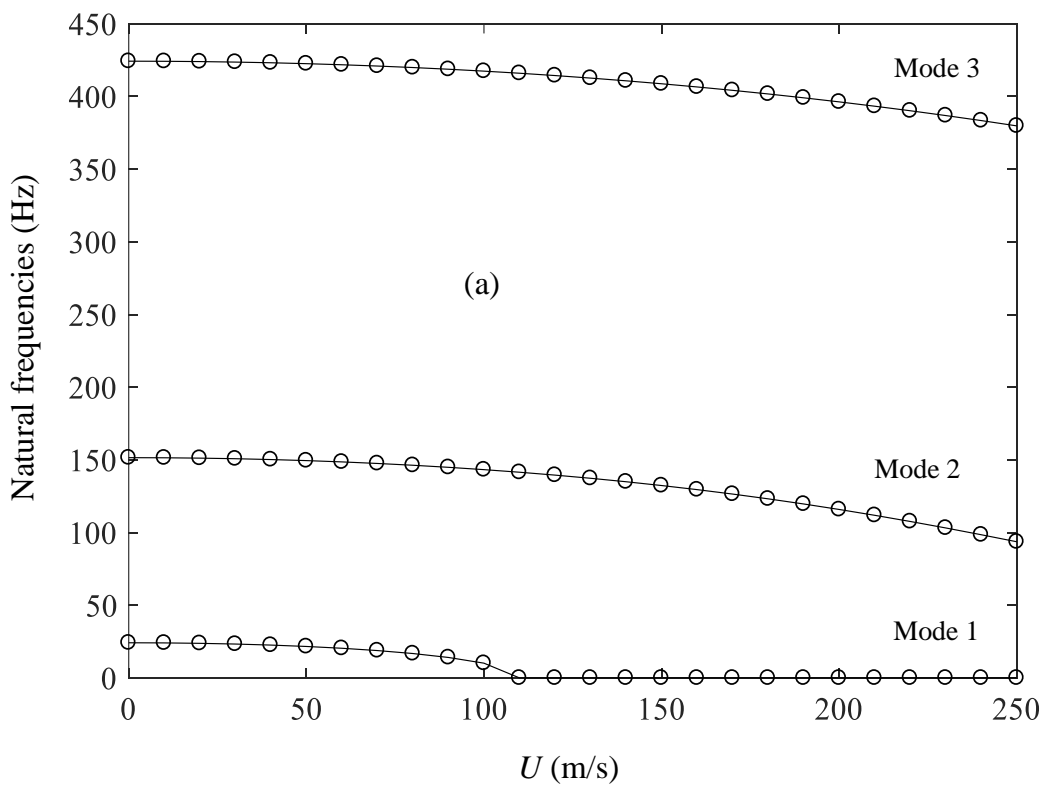


Dahmane Mouloud et al. / Current Research in Bioinformatics 2020, Volume 9: 45.55 DOI: $10.3844 /$ ajbsp.2020.45.55

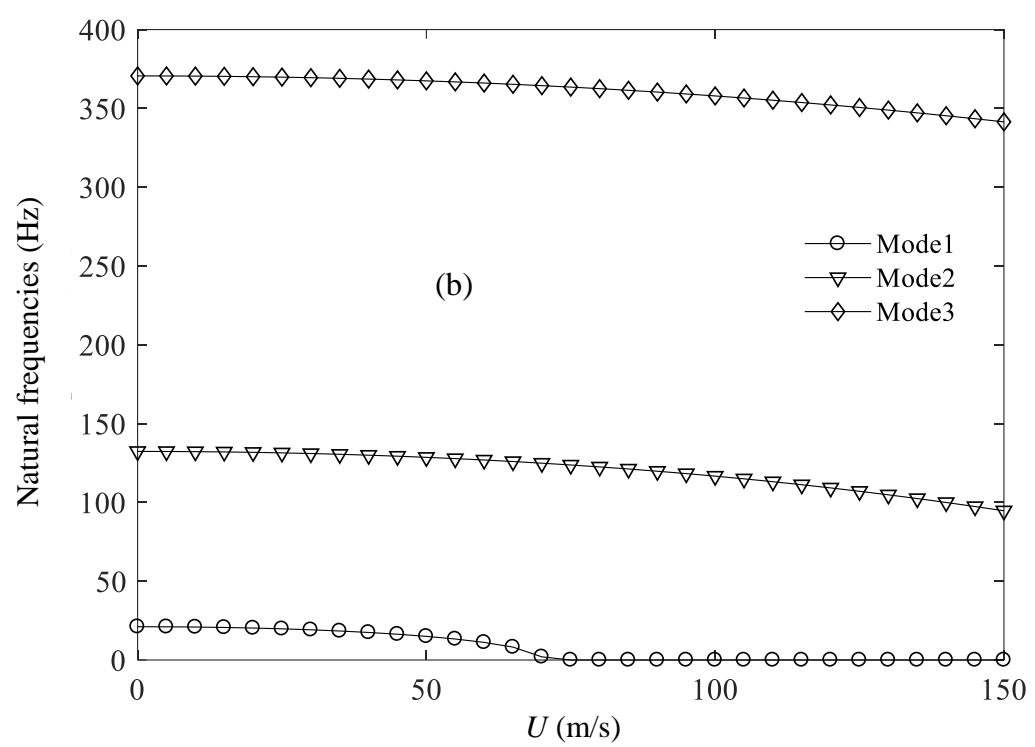

Fig. 6: Naturel frequency $(\mathrm{Hz})$ for three proper modes on fluid velocity function of cantilevered pipe conveying fluid, $L=1$, (a) $\beta=$ $0.3,(\mathrm{~b}), \beta=0.5$
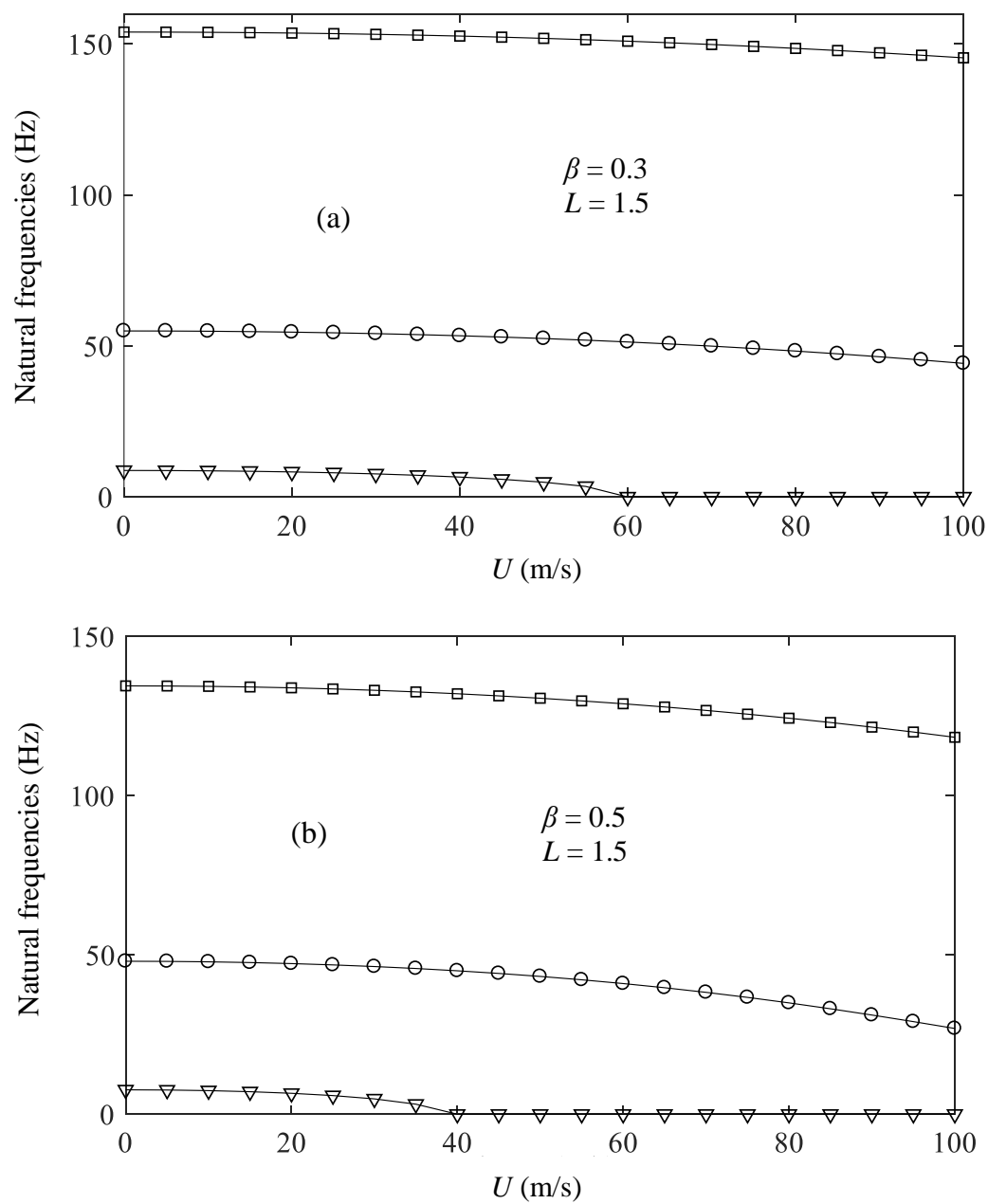

Fig. 7: Effect of length and mass ratio on the natural frequency of the cantilevered pipe at different fluid velocities 

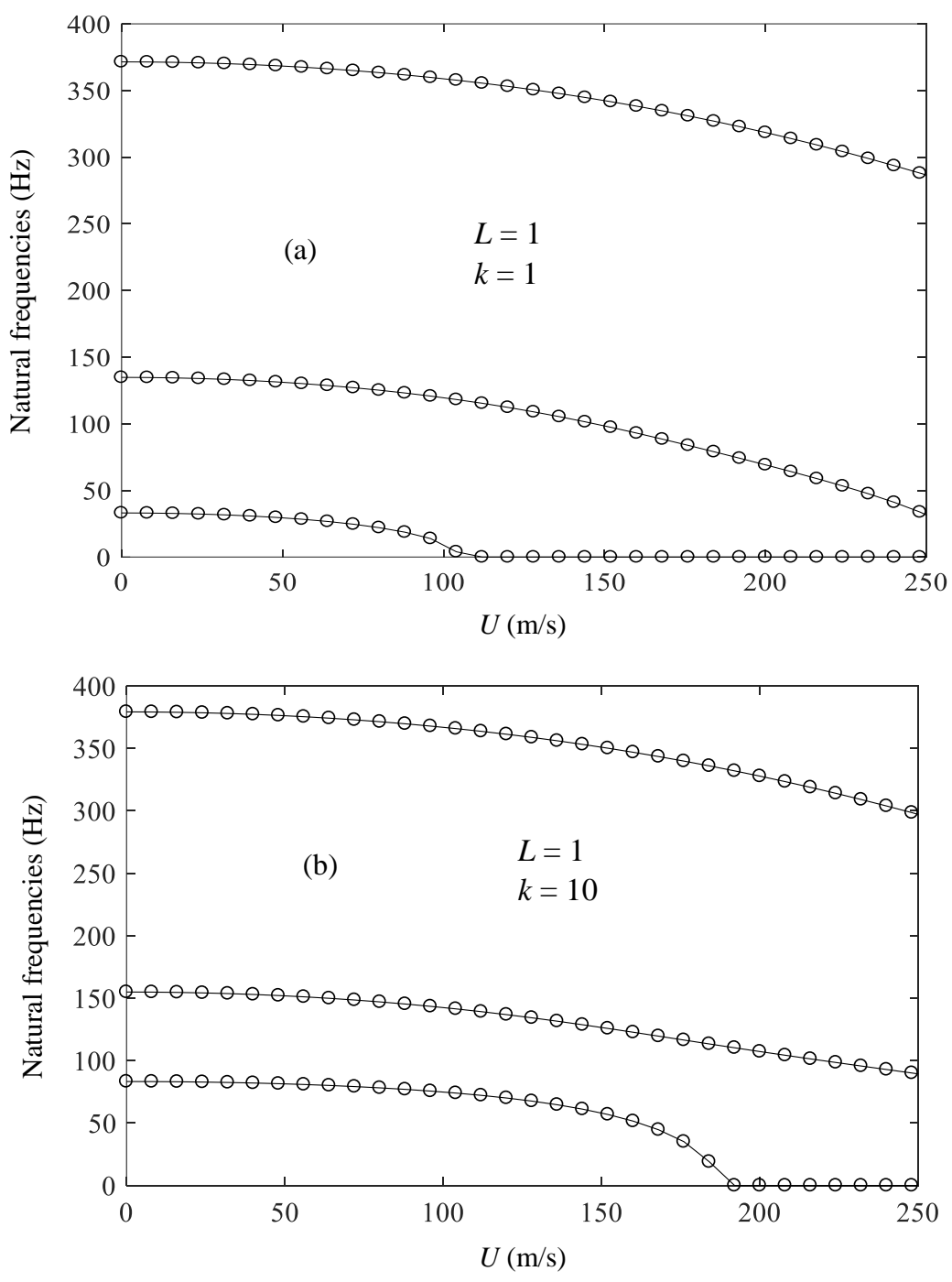

Fig. 8: Effect of foundation stiffness on the natural frequency of the clamped-free pipe at different fluid velocities, (a) $k=1$, (b) $k=$ $10, \beta=0.5$

\section{Length Effect}

We calculated the frequency of the first three Eigenmodes clamped-free pipe for two mass ratios, according to the fluid speed where $L=1.5 \mathrm{~m}$, see the Fig. 7 .

We see in the Fig. 6a that the first frequency is $25 \mathrm{~Hz}$, in the case of a fluid at rest (no flow) for a mass ration 0.3 and for $\beta=0.5$ the first frequency is $22 \mathrm{~Hz}$, Fig. $6 \mathrm{~b}$. the same remark for the second frequency which passes from $140 \mathrm{~Hz}$ to $150 \mathrm{~Hz}$, however for the third mode, the frequency passes from for $375 \mathrm{~Hz}$ for $\beta=0.5$ to $425 \mathrm{~Hz}$ for $\beta=0.3$. In this case the pipe comparable to a beam $(U=0)$ i.e., all its natural frequencies are imaginary.

\section{Foundation Effect}

We calculated the frequency of the first three Eigenmodes clamped-free pipe on an elastic foundation with two low values, according to the fluid velocity, for two lengths, Fig. $8(L=1 \mathrm{~m})$, Fig. $9(L=1.5 \mathrm{~m})$.

In the case of the flowing fluid, the first eigen modes are not similar for different mass ratio. The critical velocity is $76 \mathrm{~m} / \mathrm{s}$ for $\beta=0.5$ and for $\beta=0.3$, the critical speed is $110 \mathrm{~m} / \mathrm{s}$. when one increase the velocity, one observes first of all a stabilization of the system and all the natural frequencies see their imaginary part decreasing at the critical velocity of instability. We are now interested in the stability conditions of such system, we see in the Fig. $6(L=1)$ and the Fig. 7 that the increase in the length quickly destabilizes the system which depends on $\beta$. The effect of the elastic foundation characterized by $(k)$, the variation of the first modes of pipe under an internal flow is given by the Fig. 8 and Fig. 9 for two lengths, where mass ratio is 0.5 . So the figures show double effect of the foundation and the length. 
Dahmane Mouloud et al. / Current Research in Bioinformatics 2020, Volume 9: 45.55 DOI: 10.3844/ajbsp.2020.45.55
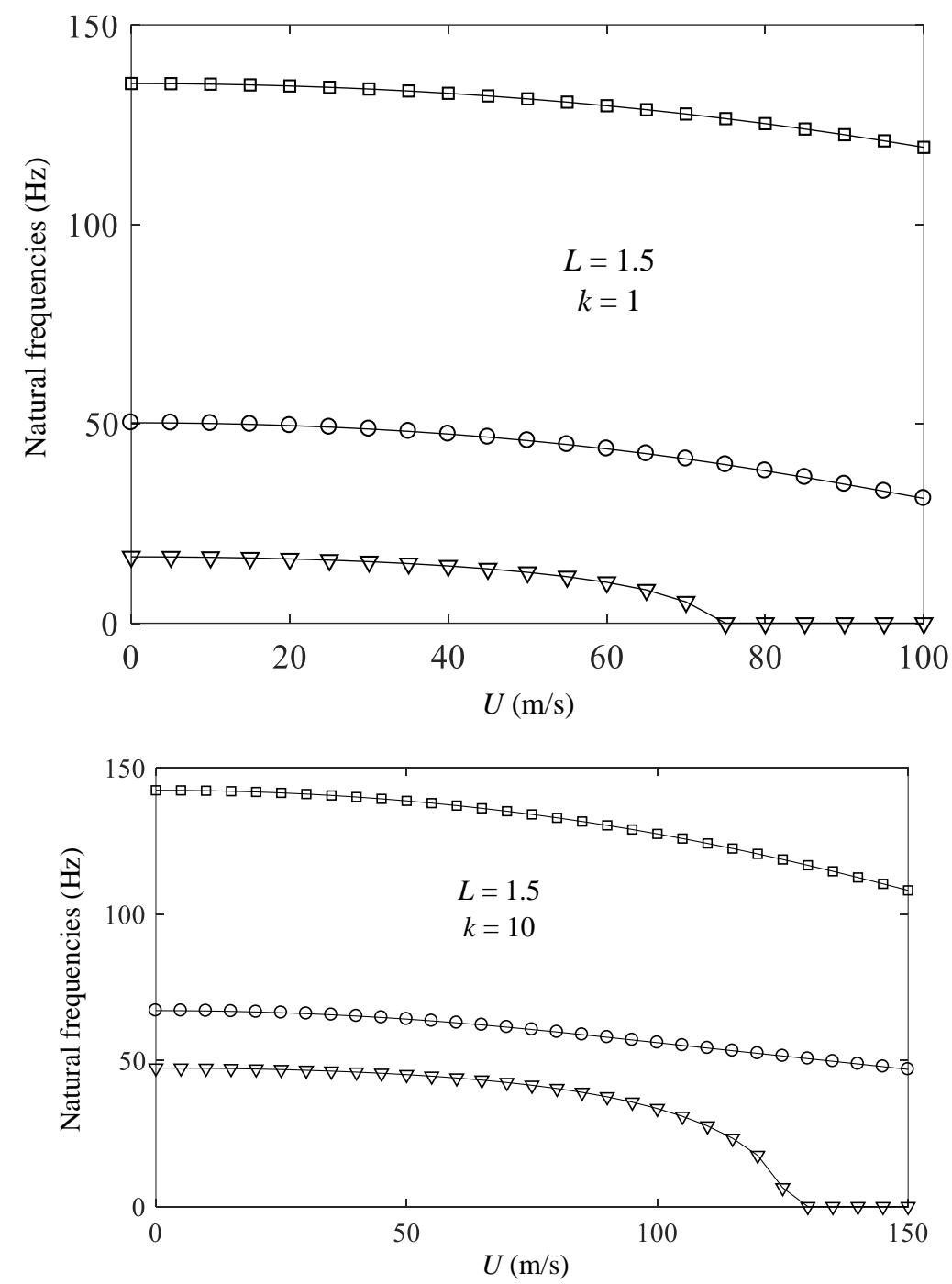

Fig. 9: Effect of foundation stiffness on the natural frequency of the clamped-free pipe at different fluid velocities, $L=1.5, \beta=0.5$

\section{Pipe Instability Parameters}

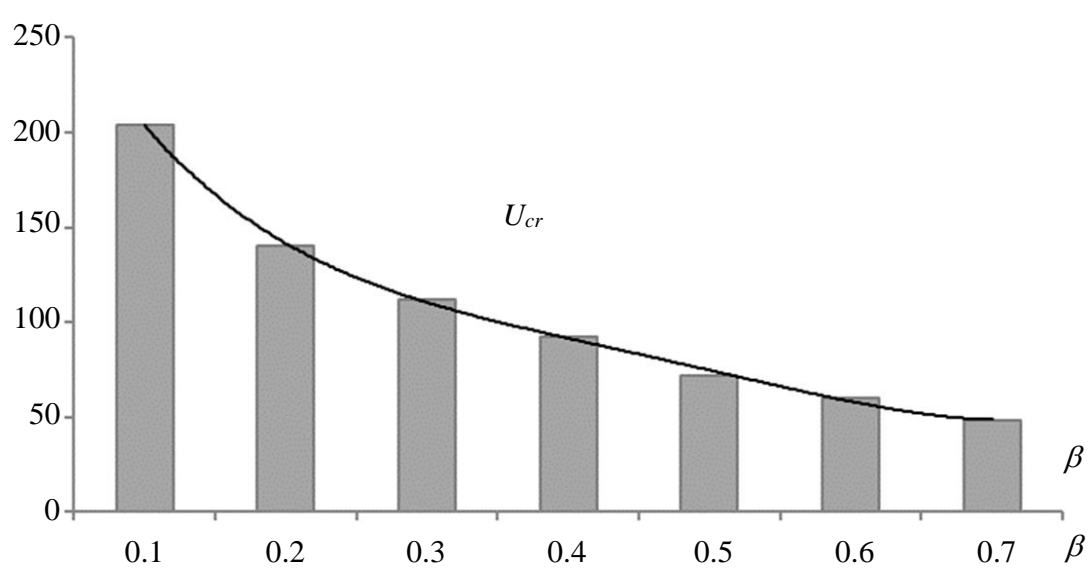

Fig. 10: The evaluation of the critical speed of instability as a function of the mass ratio for a reference length $L=1$ 


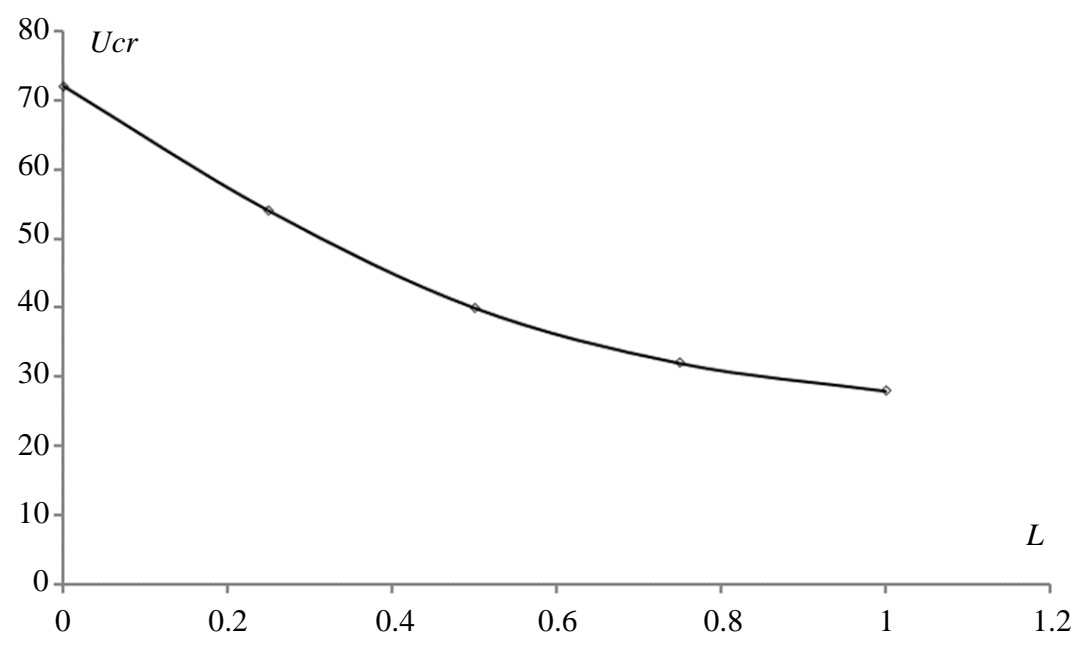

Fig. 11: Curve of the instability of the embedded-free pipe, highlighting the destabilizing effect of the length of the system
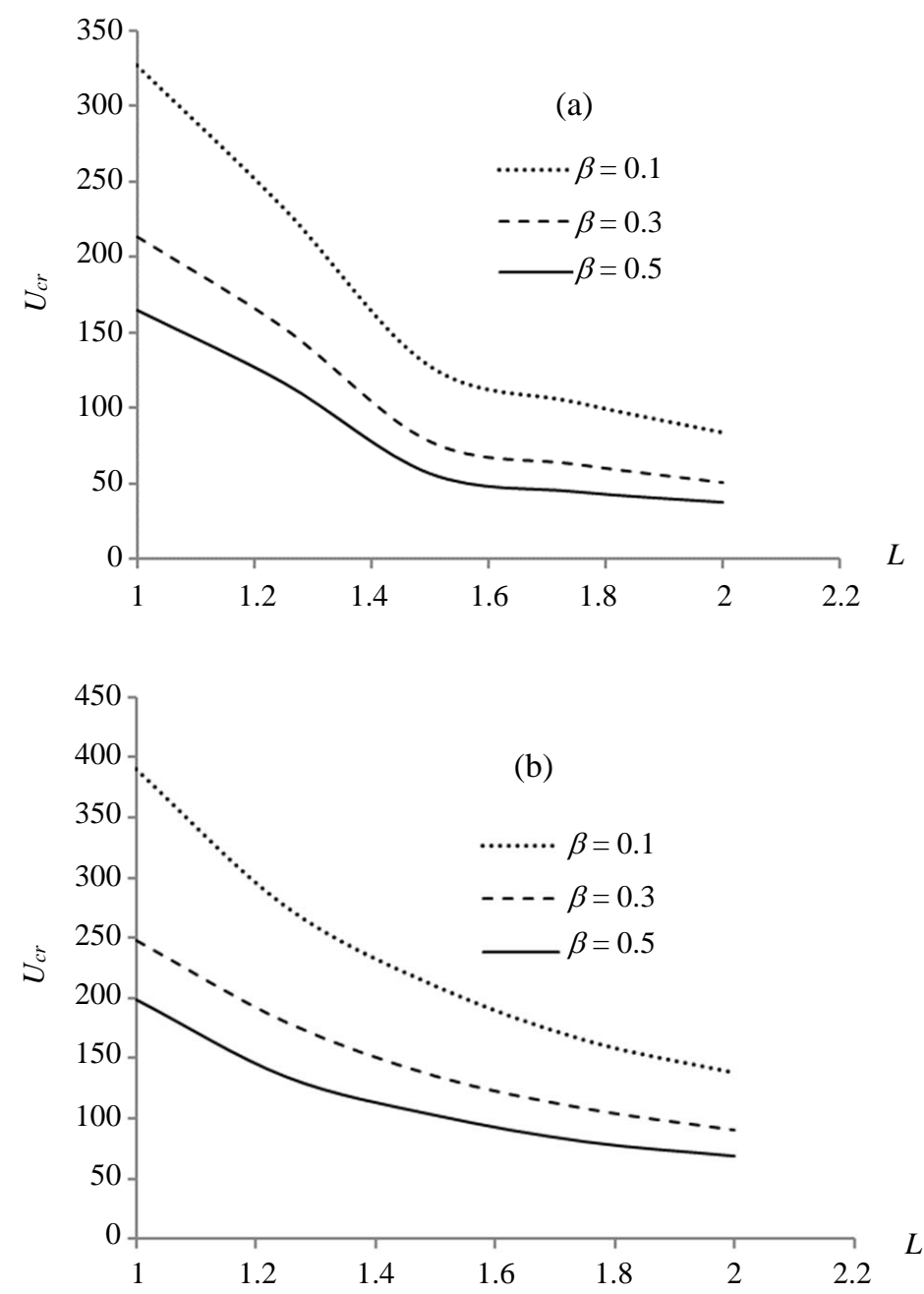

Fig. 12: Curves of the instability of the embedded-free pipe for different elastic foundations, highlighting the destabilizing effect of the length and the destabilizing effect of the mass ratio, (a) $k=1$, (b) $k=10$ 
By studying dynamics (Flutter) where the critical velocity varies according to the masse ratio in interval $[0.1 \div 0.7]$ (Fig. 10), we find that the variation curve takes a hyperbolic form. The Fig. 11 shows the variation of the critical velocity as a function of the length; we note that this curve has the same shape as the curve previous figure. We found here that the parameter $\beta$ has a destabilizing effect. Critical velocity is very sensitive to variation in length. The Fig. 12 represents the influence of the length on the variation of the critical velocity for different stiffness with different mass ratio. For $k=1$, we find that the slopes straighten around $L=1.5$. We repeated the same work for $k=10$, the curve have the same gaits.

\section{Conclusion}

The numerical aspect gives solutions in complex planes by determining the eigen-modes, an imaginary part to present the eigen-frequencies according to the fluid velocity for various parameters. The first observation that we can make that the natural frequencies of the system depends on the fluid velocity. We observe that instability appears when the velocity exceeds a threshold called the critical instability velocity. The critical velocity of the fluid varies according to the mass ratio and translates the stability of our system, while the foundation increases the system rigidity and consequently the natural frequencies and the critical speed. It has been observed that there is an absence of static buckling instability.

\section{Author's Contributions}

Dahmane Mouloud and Samir Zahaf: The authors of the idea and the research, conduced the theoretical study.

Mawhoub Soubih and Djilali Boutchicha: Extracted elementary matrix using the finite element method.

Benkhettab Mohamed: Undertook programming using the Matlab code.

\section{Ethics}

This article is original and contains unpublished material. The corresponding author confirms that all of the other authors have read and approved the manuscript and no ethical issues involved.

\section{Reference}

Chellapilla, K. R., \& Simha, H. S. (2007). Critical velocity of fluid-conveying pipes resting on twoparameter foundation. Journal of sound and vibration, 302(1-2), 387-397.

Chellapilla, K. R., \& Simha, H. S. (2008). Vibrations of fluid-conveying pipes resting on two-parameter foundation. The Open Acoustics Journal, 1(1).
Dahmane, M., Boutchicha, D., \& Adjlout, L. (2016). One-way fluid structure interaction of pipe under flow with different boundary conditions. Mechanics, 22(6), 495-503.

Doaré, O., \& de Langre, E. (2000, June). Local and global instability of fluid-conveying cantilever pipes.

Doaré, O., \& de Langre, E. (2002a). Local and global instability of fluid-conveying pipes on elastic foundations. Journal of fluids and structures, 16, 1-14.

Doaré, O., \& de Langre, E. (2002b). The flow-induced instability of long hanging pipes. European Journal of Mechanics-A/Solids, 21(5), 857-867.

Doaré, O., \& de Langre, E. (2006). The role of boundary conditions in the instability of one-dimensional systems. European Journal of Mechanics-B/Fluids, 25(6), 948-959.

Ghayesh, M. H., Farokhi, H., \& Farajpour, A. (2018a). Chaotic oscillations of viscoelastic microtubes conveying pulsatile fluid. Microfluidics and Nanofluidics, 22(7), 72.

Ghayesh, M. H., Farokhi, H., Gholipour, A., \& Tavallaeinejad, M. (2018b). Nonlinear oscillations of functionally graded microplates. International Journal of Engineering Science, 122, 56-72.

Jiya, M., Inuwa, Y. I., \& Shaba, A. I. (2018). Dynamic response analysis of a uniform conveying fluid pipe on two-parameter elastic foundation. Science World Journal, 13(2), 1-5.

Liang, F., Yang, X. D., Qian, Y. J., \& Zhang, W. (2018). Transverse free vibration and stability analysis of spinning pipes conveying fluid. International Journal of Mechanical Sciences, 137, 195-204.

Liu, Z. Y., Wang, L., \& Sun, X. P. (2018). Nonlinear forced vibration of cantilevered pipes conveying fluid. Acta Mechanica Solida Sinica, 31(1), 32-50.

Mostafa, N. H. (2014). Effect of a Viscoelastic foundation on the Dynamic Stability of a Fluid Conveying Pipe. International Journal of Applied Science and Engineering, 12(1), 59-74.

Ni, Q., Zhang, Z. L., \& Wang, L. (2011). Application of the differential transformation method to vibration analysis of pipes conveying fluid. Applied Mathematics and Computation, 217(16), 7028-7038.

Païdoussis, M. P. (1970). Dynamics of tubular cantilevers conveying fluid. Journal of Mechanical Engineering Science, 12(2), 85-103.

Païdoussis, M. P. (1981). Fluidelastic vibration of cylinder arrays in axial and cross flow: state of the art. Journal of Sound and Vibration, 76(3), 329-360.

Païdoussis, M. P., \& Besancon, P. (1981). Dynamics of arrays of cylinders with internal and external axial flow. Journal of Sound and Vibration, 76(3), 361-379.

Païdoussis, M. P., \& Curling, L. R. (1985). An analytical model for vibration of clusters of flexible cylinders in turbulent axial flow. Journal of Sound and Vibration, 98(4), 493-517. 
Païdoussis, M. P., \& Moon, F. C. (1988). Nonlinear and chaotic fluidelastic vibrations of a flexible pipe conveying fluid. Journal of Fluids and Structures, 2(6), 567-591.

Païdoussis, M. P., Semler, C., Wadham-Gagnon, M., \& Saaid, S. (2007). Dynamics of cantilevered pipes conveying fluid. Part 2: Dynamics of the system with intermediate spring support. Journal of Fluids and Structures, 23(4), 569-587.

Païdoussis, M. P. (2014) Fluid-structure interactions slender structures and axial flow. Academic Press, Elsevier, London.

Qian, Q., Wang, L., \& Ni, Q. (2009). Instability of simply supported pipes conveying fluid under thermal loads. Mechanics Research Communications, 36(3), 413-417.

Rao, S. S. (2011). The finite element method in engineering. Elsevier Science \& Technology Books.
Sadeghi, M. H., \& Karimi-Dona, M. H. (2011). Dynamic behavior of a fluid conveying pipe subjected to a moving sprung mass-an FEM-state space approach. International Journal of Pressure Vessels and Piping, 88(4), 123-131.

Sazesh, S., \& Shams, S. (2019). Vibration analysis of cantilever pipe conveying fluid under distributed random excitation. Journal of Fluids and Structures, 87, 84-101.

Wang, Y., Wang, L., Ni, Q., Dai, H., Yan, H., \& Luo, Y. (2018). Non-planar responses of cantilevered pipes conveying fluid with intermediate motion constraints. Nonlinear Dynamics, 93(2), 505-524.

Zhang, T., Ouyang, H., Zhao, C., \& Ding, Y. J. (2018). Vibration analysis of a complex fluid-conveying piping system with general boundary conditions using the receptance method. International Journal of Pressure Vessels and Piping, 166, 84-93. 